\title{
Analysing false negatives and false positives in cytopathology of breast masses along with cytohistopathological correlation
}

\author{
Nutan Patel ${ }^{1}$, Riti Sinha ${ }^{2, *}$, Navin Patel ${ }^{3}$ \\ ${ }_{1}^{1} 3^{\text {rd }}$ Year Resident, ${ }^{2}$ Associate Professor, ${ }^{3}$ Professor, Dept. of Pathology, Gujarat Adani Institute of Medical Sciences, Bhuj, \\ Gujarat, India
}

*Corresponding Name: Riti Sinha

Email: rsinha75@gmail.com

\begin{abstract}
Introduction: Carcinoma of the breast is the leading cause of death in women due to malignancy. Approximately 1,000,000 cases occur worldwide annually. Evaluation of the breast masses is of utmost important for its timely management. Fine needle aspiration cytology is a simple and reliable diagnostic method. The present study aim ED to determine the diagnostic efficacy of the fine needle aspiration cytology along with evaluating the causes of false negative and false positive in breast cytology.

Materials and Methods: The present retrospective study was conducted in G K General Hospital, Bhuj for a period of one year. Cases in which follow up histopathology was available were only included in the present study. A total 52 cases were included in the study.

Results: Fine needle aspiration cytology findings and histopathology diagnoses were correlated. Statistical analysis was done. Out of the 52 cases, only one false positive and one false negative case was found. Hence, the sensitivity of the study was $98 \%$ and the positive predictive value was also $98 \%$.

Conclusion: Fine needle aspiration cytology is a reliable diagnostic method to evaluate the breast masses. A high sensitivity and a high positive predictive value proved that a positive fine needle aspiration cytology in the breast correlates very well with the corresponding final histopathology reports.
\end{abstract}

Keywords: Fine needle aspiration cytology, Sensitivity, Positive predictive value.

\section{Introduction}

Carcinoma of the breast is the leading cause of death in women due to malignancy. Approximately 1,000,000 cases occur worldwide annually. Evaluation of the breast masses is of utmost important for its timely management. ${ }^{1-3}$ Torsten Lowhagen and colleagues way back in the 60s and 70s popularised this technique of Fine needle aspiration cytology (FNAC). This pioneering work took place in Stockholm at the Karolinska institute. ${ }^{4}$ Ease of performance, cost effectiveness, reliability, minimum invasiveness and the rapidity of its result has popularised this technique. ${ }^{5}$ The lack of false positives and the presence of nearly all true positives has established FNA as an important diagnostic procedure in the evaluation of breast masses. ${ }^{4}$ Radiological workup in the form of mammography, clinical assessment and pathological diagnosis in the form of core needle biopsy (CNB) and FNAC is the most common accepted protocol for diagnosis of breast lump. ${ }^{6}$

When all of the three of the triple test are negative or positive, there is often no need for standard excisional biopsy. ${ }^{7}$ A high diagnostic accuracy, as high as $98.9 \%$, can be achieved in the hands of an experienced cytopathologist. ${ }^{8}$ Still at times differentiation between benign and malignant lesion is quite subtle. Hence, to address this diagnostic problem, a five-tier system with categories ranging from insufficient material (C1), benign (C2), atypical (C3), suspicious of malignancy (C4), or frankly malignant (C5) are the most commonly used categories. ${ }^{9}$

\section{Aims and Objective}

1. To study the cytohistological correlation of breast masses

2. To calculate the sensitivity and positive predictive value of the study

3. To elucidate the causes of false negative and false positive cases

\section{Materials and Methods}

The present retrospective study was undertaken to study the correlation between diagnostic accuracy of FNAC and histopathology of breast lesions for a period of one year in the Department of Pathology at G K General Hospital, Bhuj. A total 52 cases were collected irrespective of their age, sex, religion, marital status, occupation and social status.

Inclusion Criteria: Cases in whom follow up histopathology was available

Exclusion Criteria: Subjects who are known cases of carcinoma breast and cases on radiotherapy and chemotherapy

FNAC were performed for all the cases using a 23 gauge needle attached to ten $\mathrm{ml}$ disposable plastic syringes and smear were made on microscopic glass slides. These smears were fixed in alcohol, and stained with haematoxylin and eosin (H\&E), and Papanicolaou (Pap) stains. On all the excision specimen, routine histopathology procedures were done and slides were stained with $\mathrm{H} \& \mathrm{E}$. The cytopathological reports were reported according to the five-tier system (C1-C5). ${ }^{9}$ The FNAC reports was correlated with the final 
histopathology reports and statistical evaluation was done. The sensitivity and the positive predictive value of the test was calculated. As there were no true negatives, the specificity, negative predictive value and diagnostic accuracy could not be calculated.

Sensitivity: The sensitivity of a test is the ability of a test to identify correctly all those who have the disease.

Positive Predictive Value: The positive predictive value of a test indicates the probability that the patient with a positive test has, in fact, the disease in question.

\section{Results}

Results of all the 52 cases in which both FNAC and histopathology reports were available, were included in the study.

1. Age distribution of female patients: The maximum number of women was in age group of 31-40years. There were no women in age below 10years and above 70years (Table 1).

2. Age distribution of male patients is shown in (Table 1).

3. Bar diagram showing the distribution of benign and malignant lesions on cytopathology in the different age groups. Benign lesions were more common in age group of 21-30 yearsand malignant lesions were common in age group of 31-40years (Fig. 1).
4. Bar diagram shows the distribution of benign and malignant lesions on histopathology in the different age groups. Benign lesions were more common in age group of 21-30 years and malignant lesions in the age group of 31-40 years (Fig. 2).

5. Five Tier category system of reporting in cytopathology (Table 2).

6. Distribution of all cases according to five-tier system is shown in (Table 3 ).

7. Cytohistological correlation of all the cases is shown in (Table 4).

8. The most common lesion in the present study was fibroadenoma (Fig. 3).

9. Carcinoma breast was the second most common lesion in the present study (Fig. 4).

10. There was one false negative case in which the cytopathological diagnosis was fat necrosis which later turned out to be invasive ductal carcinoma on histopathology (Fig. 5).

11. There was one false positive case in which ductal hyperplasia suspicious for malignancy was diagnosed that was fibrocystic disease on histopathology (Fig. 6).

12. Sensitivity in present study is $98.08 \%$.

13. Positive predictive value in present study is $98.08 \%$.

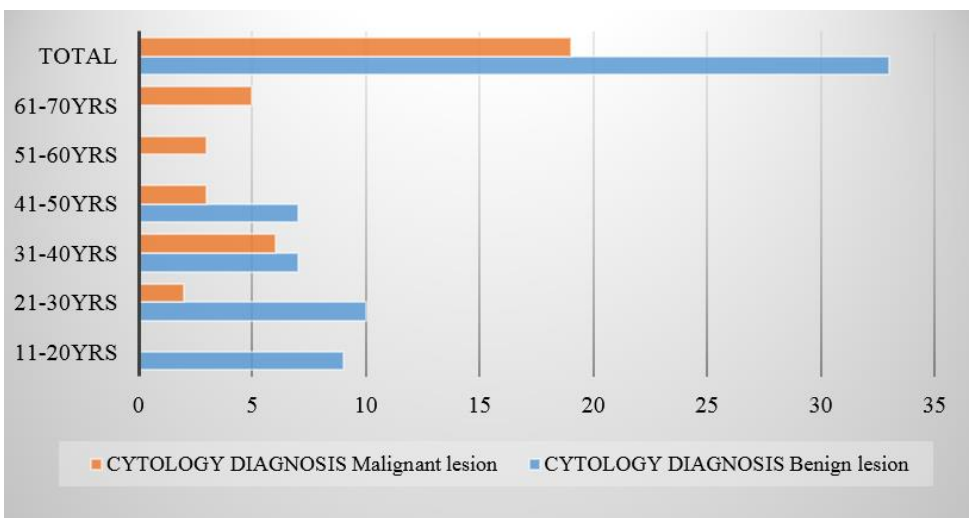

Fig. 1: Bar diagram shows the distribution of benign and malignant lesions on cytopathology in the different age group

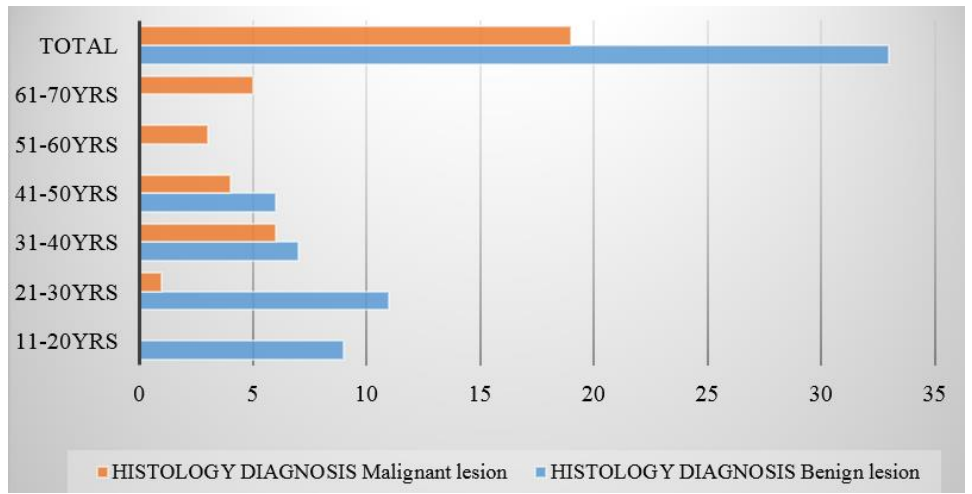

Fig. 2: Bar diagram shows the distribution of benign and malignant lesions on histopathology in the different age group 


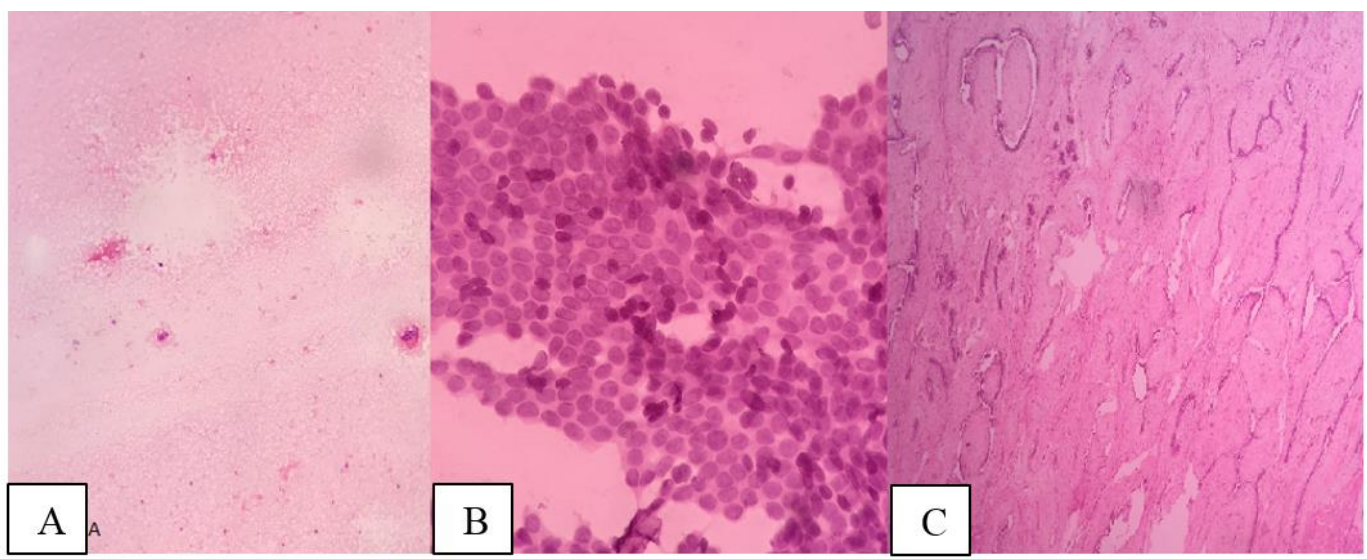

Fig. 3: A) Microphotograph showing Inadequate cytology smear; B) Microphotograph of cytology Fibroadenoma. Shows ductal epithelial cells in sheets along with myoepithelial cells (H\&E, 400 x); C) Microphotograph of histology of Fibroadenoma. The proliferation of intralobular stroma surrounds, pushes and the epithelium. (H\&E, $100 \mathrm{x})$

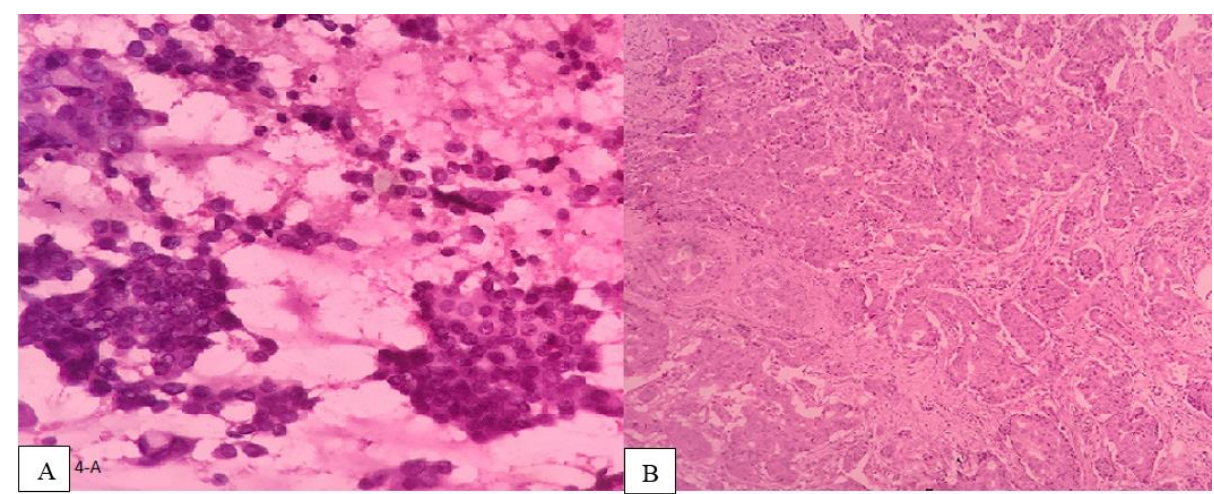

Fig.4: A) Microphotograph of cytology of Ductal carcinoma of breast (H\&E, $400 \mathrm{x})$; B) Microphotograph of histology of Invasive ductal carcinoma of breast. (H\&E, 100x)

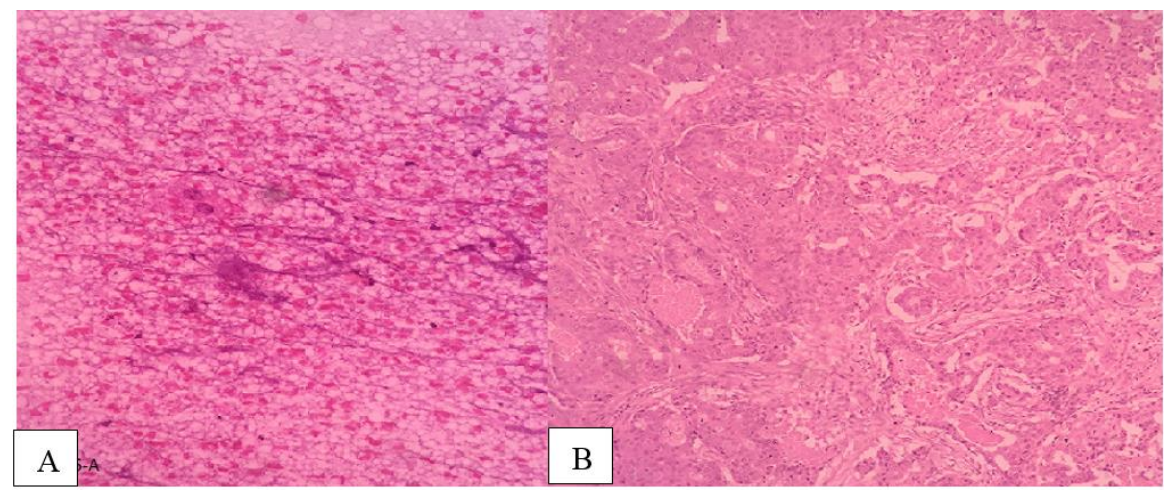

Fig. 5: A) Microphotograph showing cytology of Fat necrosis (H\&E, 400x); B) Microphotograph showing histology of Invasive ductal carcinoma of breast (H\&E, 100x) 


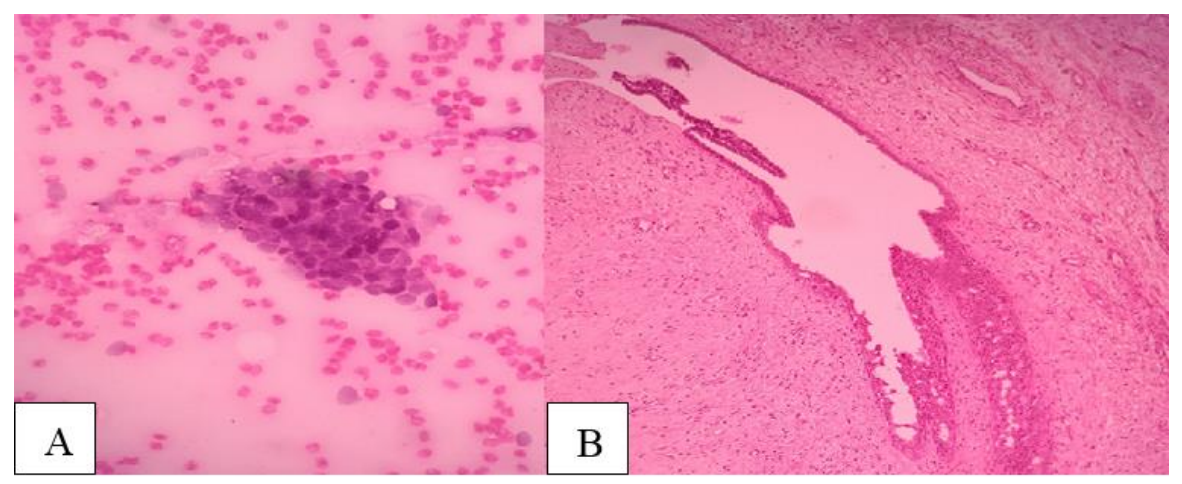

Fig. 6: A) Microphotograph showing cytopathology of Aytpical ductal cells suspicious of malignancy. (H\&E, 400 x); B) Microphotograph showing histology of Fibrocytic disease. (H\&E,100 x)

Table 1: Age distribution of female and male patients

\begin{tabular}{|l|c|c|}
\hline Age group (years) & Female & Male \\
\hline $11-20$ & 8 & 1 \\
\hline $21-30$ & 11 & 1 \\
\hline $31-40$ & 13 & 0 \\
\hline $41-50$ & 9 & 1 \\
\hline $51-60$ & 3 & 0 \\
\hline $61-70$ & 4 & 1 \\
\hline Total & 48 & 4 \\
\hline
\end{tabular}

Table 2: Five-Tier category system on cytology

\begin{tabular}{|l|c|}
\hline Category & Description \\
\hline C1 & Inadequate \\
\hline C2 & Benign \\
\hline C3 & Atypical probably benign \\
\hline C4 & Suspicious of malignancy \\
\hline C5 & Malignant \\
\hline
\end{tabular}

Table 3: Distribution of all cases according to five-tier system

\begin{tabular}{|l|c|c|c|c|c|}
\hline \multicolumn{1}{|c|}{ Cytological diagnosis } & C1 & C2 & C3 & C4 & C5 \\
\hline Granulomatous mastitis & & 4 & & & \\
\hline Fat necrosis & & 1 & & & \\
\hline Fibroadenoma & 1 & 21 & & & \\
\hline Fibrocystic & & 2 & & & \\
\hline Cytosarcomaphylloid & & 1 & & & \\
\hline Gynecomastia & & 4 & & & \\
\hline Atypical cells suspicious of malignancy & & & 2 & \\
\hline Ductal carcinoma & 1 & & & & 16 \\
\hline
\end{tabular}

Table 4: Cytohistological correlation of all cases

\begin{tabular}{|l|c|c|}
\hline & Sensitivity \% & Positive predictive value\% \\
\hline Present Study & 98.08 & 98.08 \\
\hline A Khemkaet al $^{[4]}$ & 96 & 100 \\
\hline Adetola Olubunmi Daramola, et al $^{[8]}$ & 95.4 & 100 \\
\hline I. Yusuf et, al $^{[25]}$ & 81 & 97.7 \\
\hline D.E.Obaseki, et al $^{[26]}$ & 97.4 & 100 \\
\hline ShushmaYalavarthi, et al $^{[27]}$ & 100 & 84 \\
\hline
\end{tabular}


Table 5: Comparison of sensitivity and positive predictive value with other studies

\begin{tabular}{|l|c|c|c|c|c|c|c|c|}
\hline \multicolumn{2}{|c|}{ Cytology } & \multicolumn{6}{|c|}{ Histology } \\
\hline Diagnosis & $\begin{array}{c}\text { Total } \\
\text { number }\end{array}$ & $\begin{array}{c}\text { Granulomatous } \\
\text { mastitis }\end{array}$ & Fibroadenoma & $\begin{array}{c}\text { Fibrocystic } \\
\text { disease }\end{array}$ & $\begin{array}{c}\text { Gynecomastia } \\
\text { Lactating } \\
\text { adenoma } \\
\text { with } \\
\text { infarction }\end{array}$ & $\begin{array}{c}\text { Adenomyoepithelial } \\
\text { disease }\end{array}$ & $\begin{array}{c}\text { Invasion } \\
\text { ductal } \\
\text { carcinoma }\end{array}$ \\
\hline $\begin{array}{l}\text { Granulomatous } \\
\text { mastitis (8\%) }\end{array}$ & 4 & 4 & 0 & 0 & 0 & 0 & 0 & 0 \\
\hline Fat necrosis (1\%) & 1 & 0 & 0 & 0 & 0 & 0 & 0 & 0 \\
\hline $\begin{array}{l}\text { Fibroadenoma } \\
(42 \%)\end{array}$ & 22 & 0 & 20 & 1 & 0 & 0 & 0 & 0 \\
\hline $\begin{array}{l}\text { Fibrocystic disease } \\
(4 \%)\end{array}$ & 2 & 0 & 0 & 2 & 0 & 0 & 0 & 0 \\
\hline $\begin{array}{l}\text { Cytosarcoma } \\
\text { phylloides (1\%) }\end{array}$ & 1 & 0 & 0 & 0 & 0 & 1 & 0 & 0 \\
\hline $\begin{array}{l}\text { Gynecomastia } \\
(6 \%)\end{array}$ & 3 & 0 & 0 & 0 & 3 & 0 & 0 & 0 \\
\hline $\begin{array}{l}\text { Atypical cells } \\
\text { suspicious of } \\
\text { malignancy (4\%) }\end{array}$ & 2 & 0 & 0 & 1 & 0 & 0 & & 0 \\
\hline $\begin{array}{l}\text { Ductal carcinoma } \\
(33 \%)\end{array}$ & 17 & 0 & 0 & 0 & 0 & 0 & & 0 \\
\hline
\end{tabular}

\section{Discussion}

Breast lump is a one of the common complaints with which female patients, and at times male patients present to the clinician. Breast self-examination (BSE) has created increasing awareness amongst patients in this regard. At times along with awareness, anxiety and stress also gets associated. Hence, in order to aid in quick diagnosis of the breast lump, FNAC is a reliable and useful pre-operative tool. Accurate preoperative evaluation is important as it allows for rapid management of malignant cases. ${ }^{8}$

In the present study of 52 cases with palpable breast lumps WHO underwent FNAC of the lump, followed by surgery either in the form of a lumpectomy or mastectomy, depending on the diagnosis at aspiration cytology. The aspiration cytology findings were then matched with the final histopathological report to see as to how accurate FNAC was as compared to histopathology i.e., to assess the cyto-histologic correlation.

Fibroadenoma was the most common cytological and histopathological diagnosis in the present study in females (45.8\% and $43.8 \%$ ) respectively (Fig. 3). This was followed by ductal carcinoma both in cytology and histopathology (33.33\% and 37.5\%) respectively (Fig. 4). Similar findings were also present in other studies. ${ }^{10-}$ 14

In males the most common diagnosis was fibroadenoma with one case of ductal carcinoma (Table 4).

The five tier categorization (C1-C5) (Table 2) formulated by the national co-ordinately committee for breast screening and the UK national breast screening program, serves as a common platform among all personals involved in breast diseases management. It also further emphasizes the importance of correlation with other disciplines. C2-C5 are often discussed categories, especially $\mathrm{C} 3$ and $\mathrm{C} 5$, which are grey zones in cytology. ${ }^{15}$ Our present study encountered two inadequate $(\mathrm{C} 1)$ and one false negative and one false positive case. In the present study the percentage of $\mathrm{C} 1$ (3.85\%).

Nature of the lesion, experience of the personnel taking the FNAC and the available technology are important determinant factors that affect the adequacy of the FNAC. ${ }^{7}$ Type of the lesion is the most common cause of inadequacy of FNAC accounting for $68 \%$ of inadequate aspirates. ${ }^{16}$

However clinicoradiological findings, size of lesion, nature of the aspirate, number of needle passes and expertise of the aspiration are also equally important determinants in specimen adequacy. ${ }^{17}$ Many studies have demonstrated that the number of epithelial cell clusters is an important factor in specimen adequacy and helps to lower the false negative rates in breast masses. ${ }^{17,18} \mathrm{~A}$ cut off of six epithelial cell clusters were advocated to decrease the rate of inadequate smears. ${ }^{18}$

However if specific number of ductal epithelial clusters was the criteria then up to $35-40 \%$ of true negative FNACs' would be included in the $\mathrm{C} 1$ category making patients undergo unnecessary workup. ${ }^{19} \mathrm{We}$ also do not advocate the above criteria in our present study.

We agree with this school of thought that the diagnosis of malignancy depends on the cytological features of the epithelial cells, along with adequate cellularity. This finding was similar to one other study, which included the number of ductal epithelial cells to be also helpful along with the cytological features of the epithelial cells. ${ }^{17}$

To allow proper identification of the cytological feature of epithelial cells, proper fixation, avoiding of drying artefacts and proper staining technique are ALSO equally important. ${ }^{18}$

In our present study, the cases of $\mathrm{C} 1$ category of smear was one case of fibroadenoma (Fig. 3A) and one case of ductal carcinoma in which, paucicellularity with 
presence of only a small clusters of epithelial cell was the presumptive cause.

In case of one false positive case, non-palpability of the lesion with drying were the elucidated possible factors. ${ }^{18,19}$

In the present study there was one false negative case of fat necrosis on cytology that, proved to be invasive ductal carcinoma on histopathology. On cytology moderate pleomorphism was seen with cells having round to oval nucleus with mild hyperchromatism. Moderate amount of cytoplasm was seen. Dispersed macrophages with reniform nuclei were present with few having dense non-vacuolated cytoplasm and some with vacuolated cytoplasm. Necrotic debris and calcification were also present. Epithelial cells were scant in number. False negative rate in the present study was $1.92 \%$. There exists a significant rate for false negative breast FNAC ranging from 1.2$10.6 \% .^{20-23}$

The false negative cases lead to delayed diagnosis, and delayed treatment with at times adverse outcomes. The errors leading to false negative can be either diagnostic/interpretative errors or true false negative errors. Diagnostic errors can be due to lack of experience, inability to identify the necessary cytological features needed for diagnosis, overloading of cases and at times inability to correlate the clinicoradiological findings.

We also suggest that screening error, an error in which the diagnostic cells are present but missed by the screener is also one important cause of false negativity.

Sampling error, mislocalization of the tumour, well defined tumour with minimal atypia are the other causes of true false negative factors. ${ }^{23,24}$

In the false negative case in our study, misloclization of the tumour along with sampling error was the cause of false negative. Hence, the tumour was missed and the necrotic material with calcification was sampled. This finding was similar to other studies. ${ }^{23,24}$ We also suggest that preparative errors as a result of drying artefact, staining errors and degeneration can lead to false negative diagnosis.

False positive diagnosis in aspirations in relatively low as compared to false negatives. It ranges from 0$2 \%{ }^{20,22,23}$ In the present study false positive rate was $1.92 \%$.

Ductal and lobular hyperplasia, fibrocystic changes, breast infarct and pregnancy related breast masses mostly account for false positive diagnosis. ${ }^{15,22}$ Errors leading to false positive diagnosis have not been much addressed to. We suggest that sampling errors, preparatory errors can be the other causes of false positive diagnoses.

In our study, atypical cells suspicious for malignancy was rendered in cytology in the false positive case. In this, the ductal cells with and without apocrine changes showed nuclear atypia. It could be due to drying artefact. On histopathology, the diagnosis was fibrocystic disease. Sampling and preparatory errors have been cause in the present case.

Sensitivity and positive predictive value of the present study was $98.08 \%$. It's comparison with other study is shown in (Table 5).

\section{Conclusion}

Fine needle aspiration cytology is a reliable and cost effective diagnostic tool in the evaluation of breast masses. Cytology of the breast lesions compare very well with the histopathology when done by experienced cytopathologist. They are extremely useful for accurate diagnosis of breast masses. Furthermore, reactive conditions can also mimic malignancy on cytology. Hence, the present study tried to find the plausible causes leading to false negative and false positive cases. A high sensitivity and a high positive predictive value of the study proved that a positive fine needle aspiration cytology correlates very well with the final histopathology reports and renders a definite diagnosis of the concerned disease process.

\section{References}

1. Rosai J., Breast, in: Rosai \& Ackerman's. Surgical pathology. $10^{\text {th }}$ ed. vol. 2, Missouri: Mosby;2011:16591770 .

2. International agency for research on cancer, "Globocan 2012: estimated cancer incidence, mortality and prevalence worldwide in

2012,’2015,http://globocan.iarc.fr/pages/fact sheets population.aspx.

3. I. O. Ellis, S. Humphreys, M. Michell, S. E. Pinder, C. A. Wells, and H. D. Zakhour, Guidelines for non-operative diagnostic procedures and reporting in breast cancer screening, NHS cancer screening programme, Sheffield, UK, 2001.

4. A Khemka, N Chakrabarti, S Shah, V Patel. Palpable breast lumps: fine-needle aspiration cytology versus histopathology: a correlation of diagnostic accuracy. The Internet Journal of Surgery. 2008;18:1-13

5. C. Garbar and H.Cur'e. Fine-needle aspiration cytology can play a role in neoadjuvant chemotherapy in operable breast cancer. ISRN oncology. 2013;2013:5:935797

6. (6)Ahmed I, Nazir R, Chaudhary MY. Kundi S. Triple assessment of breast lump. J Coll Physicians Surg Pak. 2007;17(9):535-8.

7. K. T. Morris, J. S. Stevens, R. F. Pommier, W. S. Fletcher, and J. T. Vetto. Usefulness of the triple test score for palpable breast masses. Archives of Surgery. 2001;136:1008-12.

8. Adetola Olubunmi Daramola, Mosebolatan Olakunboh Odubanjo, Fred John Obiajulu, Nzechukwu ZimudoIkeri and Adekunbiola Aina Fehintola Banjo. Correlation between fine-needle aspiration cytology and histology for palpable breast masses in a Nigerian tertiary health institute. International Journal of Breast Cancer. 2015;2015:742573.

9. H. Zakhour and C. Wells. Diagnostic Cytopathology of the Breast. Churchill Livingstone, London, UK, 1999.

10. Tiwari N. Role of fine needle aspiration cytology in diagnosis of breast lumps. Katmandu University Medical Journal. 2007;5:215-17. 
11. Kujur P. Fine-Needle Aspiration Cytology of the Palpable Breast Lump of 106 Cases and Correlation with Histologic Diagnosis: A Prospective Analysis. Int J Sci Stud. 2015;3:111-5.

12. Chandawale SS, Gupta K, Dharwadkar AA, Pal S, Buch AC, Mishra N. Pattern of palpable breast lesions on fi ne needle aspiration: A retrospective analysis of 902 cases. $J$ Midlife Health. 2014;5:186-91.

13. Likhar KS, Fatima A, Hazari RA, Gupta SG, Shukla U. Diagnostic role of FNAC in breast lesions. IJRRMS. 2013;3:12-4.

14. Sankaye SB, Dongre SD. Cytological study of palpable breast lumps presenting in an Indian rural setup. Indian J Med PaediatrOncol 2014;35:159-64.

15. Mendoza P, Lacambra M, Tan P-H, Tse GM. Fine Needle Aspiration Cytology of the Breast: The Nonmalignant Categories. Pathology Research Internationals. 2011;2011:547580

16. C. D. Scopa, D. Koukouras, J. Androulakis, and D. Bonikos. Sources of diagnostic discrepancies in fineneedle aspiration of the breast. Diagnostic Cytopathology. 1991;5:546-8.

17. S. Boerner and N. Sneige. Specimen adequacy and false negative diagnosis rate in fine-needle aspirates of palpable breast masses. Cancer. 1997;108:344-8.

18. I. J. Layfield, E. E. Mooney, B. Glasgow, S. Hirschowits, and A. Coogan. What constitutes an adequate smear in fine needle aspiration cytology of the breast? Cancer. 1997;81:16-21.

19. L. P. Howell, R. Gandour-Edwards, K. Folkins, R. Davis, S. Yasmeen, and A. Afify. Adequacy evaluation of fineneedle aspiration biopsy in the breast health clinic setting. Cancer. 2004;102:295-301.
20. M. Rosa, A. Mohammadi, and S. Masood. The value of fine needle aspiration biopsy in the diagnosis and prognostic assessment of palpable breast lesions. Diag Cytopathol. 2012;40:26-34.

21. S. O'Neil, M. Castelli, P. Gattuso, L. Kluskens, K. Madsen, and G. Aranha. Fine-needle aspiration of 697 palpable breast lesions with histopathologic correlation. Surgery. 1997;122:824-8.

22. T. Ishikawa, Y. Hamaguchi, M. Tanabe. False-positive and false-negative cases of fine-needle aspiration cytology for palpable breast lesions. Breast cancer. 2007; 14:388-392.

23. R. Arision, C. Cuccorese, G. Accinelli, M. P. Mano, R. Bordon, and L. Fessia. Role of fine-needle aspiration biopsy in breast lesions: analysis of a series of 4110 cases. Diagnostic Cytopathology. 1998;18:462-7.

24. S. Ciatto and S. Catania. Fine needle aspiration cytology of solid masses. Breast Cytology in Clinical Practice. 1992:75-9.

25. I. Yusuf and A. T. Atanda. Validity of fine needle aspiration cytology of the palpable breast lesions: a teaching hospital experience. Nigerian Journal of Basic and Clinical Sciences. 2014;11:36-40.

26. D.E. Obaseki, A.N. Olu-Eddo, and J.O. Ogunbiyi. Diagnostic accuracy of fine needle aspiration cytology of palpable breast masses in Benin city, Nigeria. West African Journal of Medicine. 2010;29:259-262.

27. Yalavarthi S, Tanikella R, Prabhala S, Tallam US Histopathological and cytological correlation of tumors of breast. Med J D Y Patil Univ. 2014;7:326-31. 